\title{
REINVENTAR A POLÍTICA - REINVENTAR O SISTEMA DE EDUCAÇÃO
}

\author{
Miguel G. ARRoYo*
}

\begin{abstract}
RESUMO: O texto se propõe a aprofundar-se nos referenciais teóricos com que tem sido analisada a construção do sistema de educação. $O$ foco é posto nas possibilidades e nos limites da construção de um Estado de direitos e de fortalecimento da esfera pública. Ao atrelar a construção de um sistema de educação à cooperação entre os entes federados, que possibilidades e limites coloca a garantia do direito de todos à educação? Como garantir igualdade de direitos em um padrão de poder no qual o poder dos entes federados é tão assimétrico? A análise relaciona, ainda, a construção do sistema de educação e as possibilidades e os limites da construção da esfera pública em nossa história política.
\end{abstract}

Palavras-chave: Sistema de educação. Padrão de poder. Entes federados. Esfera pública. Reinvenção da política.

\section{REINVENTING POLITICS - REINVENTING THE EDUCATIONAL SYSTEM}

ABSTRACT: This text aims at substantiating the theoretical background which has been used to analyse the construction of the educational system in Brazil. The focus is on the possibilities and limits for the construction of a Democratic State based on the rules of law and for strengthening the public sphere. By connecting the construction of an educational system to the cooperation among the political units, which possibilities and limitations are placed on ensuring everyone's right to education? How can equal rights be ensured in a power structure in which the power of the political units is so asymmetrical? The analysis also relates the construction of the educational system and the possibilities and limitations for the construction of the public sphere in our political history.

Key words: Educational system. Power structure. Political units. Public sphere. Politics reinvention.

Faculdade de Educação da Universidade Federal de Minas Gerais (UFMG). Belo Horizonte (MG) - Brasil.

Contato com o autor: <g.arroyo@uol.com.br> 


\section{RÉINVENTER LA POLITIQUE - RÉINVENTER LE SYSTÈME ÉDUCATIF}

RÉSUMÉ: Le texte se propose à s'approfondir dans les référentiels théoriques avec lesquels la construction du système éducatif a été analysée. La cible est mise dans les possibilités et dans les limites de la construction d'un État de droits et de fortification de la sphère publique. Au moment d'exploiter la construction d'un système éducatif à la coopération entre les êtres fédérés, quelles possibilités et limites placent la garantie du droit de tous à l'éducation? Comment garantir l'égalité de droits dans un modèle de pouvoir dans lequel le pouvoir des entités fédérées est aussi asymétrique? L'analyse se rapporte, tout de même, à la construction du système d'éducatif et aux possibilités et limites de la construction de la sphère publique dans notre histoire politique.

Mots-clés: Système éducatif. Modèle de pouvoir. Entités fédérées. Sphère publique. Réinvention de la politique.

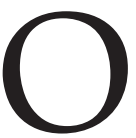

IV Seminário de Educação Brasileira (SEB) nos reúne para retomar uma tarefa política que nos tem ocupado nas últimas décadas: aprofundar-se nos limites históricos e nas possibilidades de construir e consolidar o Sistema Nacional de Educação. A tarefa proposta é dupla: de um lado discutir, aprofundar-se nos referenciais teóricos com que são analisados os processos históricos da construção e consolidação do Sistema Nacional de Educação. De outro lado, discutir, aprofundar-se sobre a necessidade de alargar esses referenciais de análise, avançar para outros, para a compreensão crítica dos processos históricos dessa construção e para avançar na sua consolidação política no presente.

Tento me aproximar das questões que a "apresentação-justificativa" do seminário nos coloca: se nas últimas décadas vinculamos a construção do sistema de educação ao reconhecimento político do direito à educação de todo cidadão e como dever do Estado, que processos dificultam a construção de um Estado de direito? Que possibilidades e limites há para o fortalecimento da esfera pública? Caminhamos para processos de publicização ou de privatização do público, dos recursos públicos para a publicização ou a privatização da educação? Para o avanço da racionalidade privada e da lucratividade do setor privado sobre áreas tradicionalmente da responsabilidade pública do Estado? A proposta do seminário é que as análises sobre o regime de colaboração sejam aprofundadas à luz dessas indagações postas na nossa realidade política.

Como coloca a justificativa deste seminário, o desafio é entender os fundamentos do conceito de regime de colaboração, considerando um país onde as desigualdades sociopolíticas e econômicas são como marcas de origem de sua herança colonial. Que regime de colaboração é possível em um cenário de desigualdades de poderes em que entes federados possuem poderes tão diferentes, tão desiguais? Ante tamanha desigualdade entre os entes federados e entre as diferentes regiões 
do país, como estabelecer um autêntico regime de colaboração? É possível? Como garantir igualdade de direitos em um sistema no qual o poder dos atores é tão assimétrico?

O seminário é um convite a que cada simpósio e cada comunicação se defrontem com estas questões. Sobretudo, que tais questões orientem pesquisas, análises, produção teórica e apontem estratégias realistas de construção-consolidação do sistema de educação.

\section{Colaboração em que padrão de poder}

A ênfase na colaboração entre os entes federados revela os aprendizados de quão complexo tem sido entregar a educação a forças políticas partidárias antagônicas. Como coabitar grupos, projetos, concepções de educação, não apenas democraticamente diversos, mas antagônicos. Como consolidar um sistema educacional se a cada novo gestor, do público, o público será outro, o direito à educação seja redefinido, os programas não tenham continuidade, os profissionais da educação sejam outros? É democrático deixar o direito à educação à mercê desse caos gestor, desses "antagonismos", da baixa política? Para estas questões tão sérias e persistentes a resposta tem sido: só coabitando, cooperando sob o mesmo teto de um eficiente sistema de cooperação entre os entes federados. Uma solução moralizante, despolitizada que ignora ou secundariza as dimensões estruturais do problema?

Nesse quadro o apelo à colaboração ou a atitudes morais, atitudinais de cada ente federado, é de uma parte o reconhecimento de que no plano institucional a colaboração não acontecerá, de outra parte é o apelo a que, cientes de que não acontecerá, ao menos o apelo à colaboração garanta um rumo de governabilidade da coisa pública. Uma governabilidade instável, desde que baseada em apelos atitudinais diante da consciência de que o problema é institucional. É significativo que esse apelo amoroso, fraterno à cooperação entre entes federados, tenha tamanha centralidade na gestão da educação, do sistema escolar. Talvez porque pensada a educação como um campo propício aos bons desejos, leva ao esquecimento dos problemas estruturais.

A ineficiência, fragilidade e vulnerabilidade do sistema de cooperação entre os entes federados nas políticas públicas, se estas fossem avaliadas com seriedade, revelariam não se tratar de um problema conjuntural, nem deste ou daquele programa (educação, por exemplo), mas de um problema estrutural de organização do poder.

Por onde avançar sem cairmos em apelos moralizantes? Aprofundando-nos na organização do poder, de que fazem parte os entes federados. Retomar as estruturas de poder que marcam a construção do sistema de educação. Podemos partir de uma constatação. 
Há uma partilha do poder assimétrico, desigual entre os estados e os municípios e a União, o que gera uma problemática assimétrica, uma gestão conflitiva dos sistemas públicos e de políticas e programas. A ênfase na cooperação pressupõe uma partilha simétrica do poder. Supõe consenso sobre a legitimidade das políticas e dos programas. A realidade tem mostrado antagonismos não apenas na gestão do direito à educação, mas na própria legitimidade desse direito e na compreensão do reconhecimento desse direito do povo.

A partilha assimétrica do poder leva a que os tempos da gestão de políticas e programas sejam diversos, até antagônicos entre os entes federados. Ao menos tempos incompatíveis, dada a partilha assimétrica do poder e a autonomia de cada um. O tempo de implementação, por exemplo, de uma política que garanta o direito da infância à educação de 3-4-5 anos ou de 0-3 anos não será o mesmo em um estado rico ou pobre, em um município rico ou pobre, grande ou pequeno, com recursos, renda ou sem renda e sem recursos. O direito à educação tem ficado à mercê dessa capacidade temporal de garantir direitos. Essa assimetria do poder leva a uma assimetria na garantia dos direitos.

Esse peso determinante da variável temporal na garantia ou não de direitos se choca com o avanço rápido da consciência de direitos e com as pressões por direitos já independentes dos condicionantes temporais tão diversos entre os entes federados. A consciência da legitimidade do direito popular à educação tem avançado mais depressa do que a capacidade de garanti-lo no modelo de cooperação entre entes com poder tão assimétrico, tão desigual.

As lutas por escola indígena, quilombola, do campo ou de uma favela não se vinculam à partilha tão desigual de poderes, nem a apelos de cooperação. As lutas por direito à escola pública têm superado as divisões, os recortes entre as esferas pública municipal, estadual e federal. Avança a consciência popular de um direito sem recortes e quintais gestores.

Em outros termos, o regime de cooperação em vez de garantir a igualdade de direitos está reforçando a sua desigualdade. Dependendo do ente responsável pelo dever de garantir o direito, seu grau de garantia poderá variar entre garantia ou não garantia, garantia já ou no longo prazo ou nunca. Esta é a denúncia que vem dos movimentos sociais do campo, de ribeirinhos e das florestas ou de quilombolas, indígenas, cidadãos dos pequenos e pobres municípios e até de estados.

\section{A organização do poder e a garantia de direitos}

A diversidade de tentativas de construção do sistema nacional estruturado, cooperativo de educação tem destacado as tensas relações entre o sistema educacional e 
o sistema político. Há percepção de que a lógica esperada de um sistema articulado de educação não se acerta com a lógica estruturante de nosso sistema político ou das articulações políticas entre os entes federados. Tentar construir um sistema de educação articulado em seus órgãos e níveis, ignorando o sistema político a que está amarrado, tem se mostrado inconsequente. Neste sentido, significa um avanço colocar a questão nuclear na análise das possibilidades e dos limites da cooperação entre os entes federados em nosso sistema político para avançar na compreensão das possibilidades e dos limites da construção de um sistema de educação articulado.

Nessa perspectiva a questão nuclear passa a ser que lógicas, que racionalidades, que intencionalidades e que unidade, coerência e operacionalidade, que valores prevalecem em nosso sistema político ou na especificidade histórica das relações políticas entre os entes federados? Pôr a ênfase na compreensão do sistema político poderá redefinir um olhar fechado no sistema educacional como se operasse por uma dinâmica própria apenas tocado, condicionado acidentalmente pela lógica do sistema político. Poderá ainda redefinir uma crença: esperar que a lógica de cooperação, de coerência, de unidade e articulação bem-sucedida no sistema educacional resista a outras lógicas externas, do sistema político em concreto.

Seria fecundo pesquisar o que há de avanço no reconhecimento dessa tensão entre o sistema de educação e o sistema político quando se apela à cooperação entre os entes federados e o reconhecimento do peso determinante do sistema político sobre o sistema de educação. Por aí será possível superar certa tendência a pensar o sistema de educação como uma construção teórica. Sistema do qual, se bem alicerçado em uma coerente construção teórica sobre o que é sistema, sua configuração como tal estará garantida. Ao reconhecer o entrelaçamento entre o sistema de educação e o sistema político está se avançando para a necessidade de entender mais esse entrelaçamento histórico não apenas recontando leis, ordenamentos, constituições, diretrizes e LDBs, mas colocando a articulação no cerne do sistema político, na organização do poder. Apelar e aprofundar que papel tem cumprido a colaboração entre os entes federados na organização do poder e na especificidade do padrão de poder construído e reforçado ao longo de nossa história nas relações sociais e nas políticas de dominação-subalternização dos coletivos populares, dos trabalhadores das periferias urbanas e dos campos aos quais o sistema de educação básica pública se destina. Aprofundar-se nessa história política será o caminho mais fecundo para entender a lenta e desestruturada construção de nosso sistema educacional.

Essa organização do poder a que historicamente tem sido atrelada a construção do sistema de educação não tem trazido problemas apenas conjunturais de descontinuidade, mas tem se tornado uma questão estrutural. A ênfase na sempre tentada cooperação entre os entes federados tem privilegiado análises conjunturais passíveis de serem superadas com atitudes, condutas, compromissos e até progredindo para uma 
cultura solidária entre os entes federados. Na medida em que as pesquisas e análises de políticas avançam para ir além de ver um problema conjuntural e reconhecerem que se trata de um problema estrutural, as recomendações não podem limitar-se a gestos de solidariedade, de cooperação ou articulação, mas exigem outro modelo, outra estrutura institucional. Outra organização do poder que viabilize a construção de um sistema de educação pública, garantia de direitos.

Por onde tem passado esse problema estrutural nessa organização do poder a que tem sido atrelado o sistema educacional em nossa história? Passa por fazer da cooperação entre os entes federados não tanto um exercício de democracia administrativa da coisa pública, mas por ser um dos mecanismos da estabilidade ou da tênue estabilidade governamental.

Os serviços públicos têm cumprido o papel de atenuar problemas estruturais de organização do poder, de instabilidade governamental, constituindo-se ao longo de nossa história política em moedas de troca de favores, de barganhas para a tênue estabilidade governamental e política nessa instável organização do poder. Esse persistente problema estrutural e esse uso e abuso dos serviços públicos mais básicos, como saúde, educação, transporte, nessa organização do poder têm sido um dos condicionantes mais determinantes da forma como vem se configurando o sistema educacional e as políticas sociais para os setores populares. Uma organização histórica modernizada e sofisticada do poder cuja síntese seria "Coronelismo, enxada e voto"? (LEAL, 1948)

\section{Possibilidades e limites de um pacto político}

O seminário sobre políticas de responsabilização, regime de colaboração e Sistema Nacional de Educação parte de uma interrogação de fundo: quais as possibilidades e os limites de um pacto político? Para aproximar-nos dessa questão será necessário colocar-nos outra: em que tempos políticos estamos?

Francisco de Oliveira tem sido um dos analistas que têm se aproximado com uma postura crítica radical da política em nossos tempos. Na sua obra clássica, Crítica da razão dualista, e especificamente no texto "A política em uma era de indeterminação" (2003a), mostra os limites da política e de consensos políticos: “Na relação entre classe e interesse a representação foi para o espaço; a possibilidade da formação de consensos tornou-se uma quimera, mas num sentido inteiramente dramático, isto é, não é anúncio de dissenso e não gera política". O autor insiste em suas análises que estamos em tempos de limites ao dissenso, a consolidação da esfera pública democrática, logo de limites às tentativas de uma negociação pública e publicizada sobre o fundo público, sobre as destinações da riqueza social. Tempos de limites ao reconhecimento de outros sujeitos sociais, políticos, culturais. Limites a reconhecer 
outras alteridades. Logo, limites radicais ao consenso político nesse radical esvaziamento da política e do dissenso.

O tema do seminário aponta que estaríamos em tempos de consensos na sociedade civil e entre os entes federados. As análises políticas mais críticas nos alertam de que, apesar do chamado associativismo na sociedade civil organizada, os conflitos estão expostos, de que estamos em tensos conflitos entre classes, de que o conflito social não perdeu sua potência política, de que as tradicionais alteridades estão postas por mais que se pretenda ocultá-las em relações difusas que esvaziem a potência política do momento. As análises políticas insistem em que estamos mais em um estado de exceção do que de cooperação, que as cidades são os lugares por excelência de cruéis exceções e desigualdades abissais de moradia, renda, trabalho, alimentação, saúde, educação, que são reprimidas as tentativas de dissensos em movimentos de lutas por esses direitos. Será possível administrar esse estado de exceção pela cooperação e por políticas de responsabilização consensuada?

O seminário deixou exposto que estas questões nos interpelam no próprio campo da educação quando se pensa na consolidação do Sistema Nacional de Educação, mais justo, democrático e igualitário. A quem apelar para que essa longa empreitada seja realidade? Apelar para o discurso edificante da cultura solidária, da solidariedade moral e responsável de combate à pobreza, à exclusão, pela inclusão na escola pública de qualidade? Apelar à cooperação de todos pela elevação das médias de acertos em provas e provinhas Brasil? Pela alfabetização de toda criança na idade certa ou por que todo aluno atinja as expectativas de aprendizagem na série certa? Tarefas que não seriam do Estado só, da política, mas de uma campanha de cooperação, solidariedade moral de todos pela educação? Pelas boas consciências cooperantes?

Para quebrar o sossego desse apelo aos homens de boa vontade ou às boas consciências pacificadas com os tempos de exceção e de indeterminação, o seminário mostrou que a consciência política crítica está acordada, não pacificada, nem acreditando no edificante discurso da cultura solidária e da solidariedade e responsabilização moral de um todo indistinto, para além das tensões de classe postas e repostas pelos trabalhadores e pela diversidade de movimentos sociais. O pensamento educacional forjou-se nos mesmos embates e conflitos que alimentaram o pensamento crítico, social e político. A quem interessa paralisar o trabalho dessa crítica sob a paralisante solidariedade moral de um todo indistinto? O pensamento educacional é chamado a não renunciar à tarefa da crítica, a abrir-se a novas indagações, sobretudo em tempos nos quais a articulação entre trabalho, vida, direitos à terra, teto, saúde, educação, cidadania se tornou tão tensa, na ameaça de uma articulação sonhada, mas quebrada. Se essa articulação foi quebrada, se o movimento de pressão pela educação, direito de todo cidadão e dever do Estado, foi enfraquecido, erodido, 
como analisá-lo, aprofundá-lo e superá-lo sem a retomada da tarefa da crítica? Sem repor a crítica, as análises e as propostas, no campo da política? Mas que crítica cabe em tempos de esvaziamento da política? Os apelos à solidariedade moral não são um gesto de esvaziamento do dissenso e da política?

\section{Tempos propícios à colaboração?}

O seminário, ao escolher como tema políticas de responsabilização, regime de colaboração e Sistema Nacional de Educação, traz um apelo a perguntar-nos em que tempos sociais e políticos se apela à cooperação entre os entes federados para a construção de um sistema articulado de educação? Por aí se interpretam os rumos da realidade social e política do mundo em que habitamos? Qual o poder explicativo dos conceitos que legitimam essa linha de análise?

Boaventura de Sousa Santos (2006) nos adverte de que "o contrato social, em seus critérios de inclusão e de exclusão [...] enquanto paradigma social, político, cultural atravessa desde mais de uma década um período de grande turbulência que incide não apenas sobre seus dispositivos operativos, mas também nos seus pressupostos". Essa turbulência estaria afetando os valores do apelo à cooperação. $\mathrm{O}$ autor aponta: "O nível dos pressupostos, o regime geral de valores parece não resistir à crescente fragmentação da sociedade, dividida em múltiplos apartheids, polarizada ao longo de eixos econômicos, sociais, políticos, culturais e religiosos. Não só perde sentido a luta pelo bem comum como também parece perder sentido a luta por definições alternativas de bem comum. A vontade geral parece ter-se transformado numa proposição absurda" (p. 324). Uma advertência a ser levada em conta para rever o pensamento educacional tão ciente do bem comum e do apelo à vontade geral: todos pela educação.

Pensemos em um dos traços marcantes nas análises ainda recentes: neoliberalismo e educação. Avançamos nas análises sobre como o neoliberalismo vem afetando o desmantelamento do sistema de educação pública, na medida em que leva à privatização do público, à anulação da política e das políticas educativas. Francisco de Oliveira já nos advertia, na Crítica da Razão Dualista, sobre o caráter antidemocrático, totalitário, antipúblico e antipolítico do que denominou "totalitarismo neoliberal". O campo da educação foi e continua um território propício a esse totalitarismo neoliberal que foi destruindo décadas de políticas, de práticas, de concepções democráticas, de politização da educação, de situá-la no campo dos direitos de todo cidadão e do dever do Estado. Uma construção que se contrapunha ao uso e abuso do Estado, do público, da educação especificamente na ordem e no estilo patrimonialista e ao controle da esfera pública pelo jogo decisório fechado das classes dominantes. Esses avanços construídos com tanto esforço partiam dessa constatação histórica de 
ter sido construído nosso sistema educacional visceralmente articulado a essa ordem patrimonial, de apropriação e num jogo de decisões e partilhas entre as classes dominantes gestoras do público em cada esfera da nossa ordem federada.

Como ignorar essa desconstrução patrimonialista tentada nas décadas recentes e apelar agora à reconstrução de um sistema articulado de educação apelando à cooperação entre os entes federados quando ainda não foi superado o embate com essa ordem patrimonial? Quando o público, a política e as políticas continuam entregues a esses jogos patrimonialistas mais sofisticados do que no passado de partilhas do Estado e de suas instituições entre elas e com destaque ao sistema de educação? A ordem patrimonial modernizada e sofisticada em nome da governabilidade. Trazer o debate para a relação entre sistema público de educação e cooperação entre os entes federados exige retomar essa história das tentativas de desconstrução da relação entre sistema de educação, Estado e política apropriados pela ordem patrimonial. O Estado, a política, as políticas educacionais, a constituição da esfera pública e da escola pública estão livres desses arranjos de privatização e apropriação patrimonial das classes dominantes? Que sentido político têm esses apelos a sua cooperação?

O neoliberalismo leva a destruição do público a formas totalitárias, repõe em lógicas modernas o controle patrimonialista do Estado, do público e das instituições e políticas públicas no controle das instituições e dos fundos públicos. As políticas neoliberais têm recortado as possibilidades do controle democrático, público, dos fundos públicos, recortando até a gestão democrática da gestão das instituições e políticas públicas. Nesse quadro em que se opera a privatização do público, o caminho seria o apelo à cooperação dos entes que apadrinham essas políticas neoliberais?

O debate reposto sobre essa cooperação como solução coloca a necessidade de ir além e avançar na compreensão desse quadro de privatização do público, de disputas pelos fundos públicos. Coloca a necessidade de ampliar os mecanismos de controle democrático, popular, realmente público dos fundos públicos, das instituições públicas, incorporando nessas disputas os sujeitos realmente públicos, democráticos, organizados politicamente na pressão sobre o Estado para cumprir seus deveres de garantir esses direitos. Exige saber quem é quem na defesa do público e quem é quem na privatização dos fundos e das instituições públicas. Do próprio Estado.

Maria Célia Paoli (2006, p. 135) lembra-nos: “Sobretudo, isto significaria uma mudança considerável em uma sociedade cuja história de pactos com o Estado aparece estruturada de modo autoritário, raramente exigindo das elites algo mais do que a entrega de falsos anéis, de modo a reter a real negociação dentro de sua própria classe, entre pares". Exige saber em que tempos estamos de pactos privatizantes e de uma cultura política e mediática da desnecessidade do público, especificamente da escola pública, do gasto desnecessário com um sistema de saúde ou de educação 
públicos tão desqualificados como ineficientes. As notícias de cada noite encarregam-se de criar a consciência nacional de que a esfera pública em geral e especificamente a escola pública são desnecessárias. São um peso inútil, gastos inúteis de fundos privados.

A essa exaltação neoliberal da desnecessidade do público se contrapõe a experiência histórica dos trabalhadores, incluindo os trabalhadores em educação, e dos diversos coletivos segregados do público. Eles afirmam sua experiência histórica coletiva da urgente necessidade do público. Consequentemente afirmam a necessidade de serem reconhecidos os primeiros defensores do público, de estarem presentes como população organizada na construção do público, no controle da efetivação do dever do Estado na garantia de todos os seus direitos. Difícil é encontrar nesses coletivos o apelo a entrarem em qualquer estratégia de regulação pactuada. Como coletivos organizados, têm experiências acumuladas de que toda estratégia de regulação pactuada do público como espaço de direitos significa fazer do público espaço do mercado. Reduzir os direitos ao jogo do mercado: terra, moradia, trabalho, saúde, educação. Não é por aí que estão em disputa esses direitos e até o direito à educação? Abrir esses espaços públicos ao mercado para os interesses de "todos". A saúde, a educação, os direitos mais básicos disputados como mais um campo de lucro. A destruição mais radical de sua condição de espaços públicos de direitos. A desnecessidade do público e do Estado para sua apropriação. Mais um capítulo da longa e tensa apropriação do público pelos interesses privados. Mas também um capítulo a mostrar as contradições que sempre transpassaram essa construção. Faltam pesquisas e análises que mostrem a especificidade dessas contradições ao reconstruir a história da construção do sistema de educação pública. História tensa de concentração política, de disputas por direitos negados, por entraves para a entrada e permanência dos setores populares, dos trabalhadores, e por brutais segregações e reprovações quando ousaram entrar.

\section{A indistinção da esfera pública}

Passemos a outro ponto que pode aprofundar-se na tensa história da construção do sistema desarticulado, indistinto de educação: a história da indistinção da esfera pública.

A construção do nosso sistema público de educação acompanha a história da construção-indistinção da esfera pública. Pesquisar e teorizar mais sobre essa relação seria uma pista para entender as possibilidades e os limites da construção e consolidação do sistema educacional. Estamos sugerindo que, ao tentar aproximar-nos das possibilidades e dos limites da colaboração entre os entes federados no campo da educação, é uma exigência levar a análise crítica para a disputa política pelos 
fundos públicos, pela esfera pública, pelo sistema público de educação. A sociologia política oferece-nos análises para entender essa relação.

Uma das críticas do Chico de Oliveira, ao longo de sua obra, é a indistinção do público e do privado em nossa história, como característica da política brasileira. Mais, ainda, a destruição do público e a consequente anulação da política. Não é esse o caminho da indistinção do sistema educacional em que ainda hoje caminham as políticas públicas de educação? Logo em tempo de avanço da consciência popular do direito à escola, à universidade, à educação, avança a indistinção do público e do privado. Até na construção de escolas de educação infantil se apela para as parcerias público-privadas e o direito à escola pública é condicionado à cooperação de todos pela educação. Os tênues contornos do público, da esfera pública, vão se desmanchando no apelo a cooperações de todos no neodesenvolvimentismo, indistintamente diluindo o confronto de forças, de classes, de projetos de sociedade, de campo, de cidade. De educação. Um processo de desresponsabilização pública do Estado e de anulação da política, da esfera pública e da escola pública. Diluição do dever do Estado e dos contornos específicos do público. Projeto que se tentou construir nas últimas décadas e por que lutam tantos intelectuais e docentes junto com os movimentos sociais.

Quando o dever do Estado, a política e a esfera pública perdem seus contornos, as políticas educativas e a escola pública se descaracterizam, na qualidade de públicos. A ênfase em todos cooperando pela educação anula o jogo político e dilui os contornos de classe e os contornos entre o público e o privado. Não é por acaso que se insiste tanto em pactos, em cultura solidária, em todos pela educação, logo em tempos em que as classes dominadas reagem a ser objeto de manipulação e de dominação e se afirmam em lutas por políticas públicas de direitos a terra, teto, trabalho, renda, vida, escola e universidade públicos. À pressão por políticas públicas, espaços públicos, responde-se com a indeterminação da política e do público, com a regressão dos direitos do trabalho, com a entrega da garantia dos direitos sociais, culturais, educacionais, as parcerias público-privadas. Ante a dinâmica de coletivos, classes, movimentos em confrontos de projetos de sociedade, de Estado, do público, oferece-se a paz incolor da cooperação de todos, da cultura solidária, tão cara ao campo da pedagogia. São os novos horizontes de esfera pública e da política despolitizados.

Para equacionar esses vínculos entre construção do sistema público de educação e da esfera pública uma questão é central: por onde tem passado a indistinção e destruição da esfera pública? Pela construção e reconstrução social privatizante da sociedade. Uma ideologia antiestatal, antipolítica de Estado, antipúblico, que invade até a gestão do sistema de educação. Essa produção-reprodução antipública da sociedade produz e é produzida pela socialização vigente que desprestigia o público, a esfera pública, o sistema público de saúde ou de educação. Por aí passam sua 
fraqueza e a deslegitimidade da esfera e da escola públicas nas elites, nas camadas médias, que desprezam a escola pública e a esfera pública, e nos próprios formuladores de políticas educativas e até nos gestores do próprio sistema. Essa socialização antipública vigente, que eleva o privado e elimina o público, tem sido uma constante em nossa história republicana e democrática, marcada por uma apropriação privada do Estado, por uma construção social privatizante da diversidade de áreas sociais, incluindo a educação. O ideário liberal e neoliberal vem tentando a destruição final da esfera pública, que em nossa história sempre foi fraca e sempre ameaçada.

Da pesquisa e da análise de políticas se espera que se explicitem e aprofundem as relações entre a lenta e desfigurada construção do nosso sistema nacional de educação e essa história de desvalorização e destruição da esfera pública.

\section{Padrões de socialização que dispensam a esfera pública}

Pensemos em outro traço de nossa formação social que tem enfraquecido a construção-consolidação do nosso sistema de educação pública e da esfera pública.

Por onde passa a fraqueza e essa ameaça constante da esfera pública? Esta seria uma indagação fecunda para entendermos a fraca e sempre ameaçada construção-reconstrução do sistema público de educação. Passa não tanto pela falta de visão do público das elites que controlam os entes federados, mas passou e passa pelos processos de reprodução material hegemônicos em nossa história. Entre esses processos mereceriam destaque os padrões de trabalho e de cidadania na produção e reprodução da sociedade. Para entender a relação entre a construção do sistema de educação e esses padrões de trabalho e de cidadania, tais padrões terão de ser vistos como processos de socialização, de produção de tipos de trabalhadores e de cidadãos.

Todos os estatutos legais justificam a construção do sistema educacional à garantia do direito ao trabalho e à cidadania ou a socialização para o trabalho e a cidadania, porém pouco se tem pesquisado a que padrões de trabalho e de cidadania têm se vinculado na produção de nossa sociedade. Sobretudo, pouco se tem pesquisado sobre a que padrões de trabalho e de cidadania têm sido atrelados os trabalhadores e os coletivos populares, supostos destinatários do sistema educacional público. Essa carência de análises nesses padrões e na específica formação dos trabalhadores e dos coletivos populares tem enfraquecido as análises sobre a construção histórica de nosso sistema escolar. Submeter os trabalhadores e os setores populares a padrões de trabalho e de cidadania tem operado em nossa história como processos de socialização ou como componentes eficazes no padrão de socialização para legitimar e mantê-los em processos de subalternização, de estado-condição de sobreviventes, sem controle da produção de seu viver. Socializados para serem reduzidos 
à condição de coisas, de mão de obra precarizada e descartável. Ou socializados na condição de subcidadãos. A proclamada função de socializar para o trabalho esquece-se de aprofundar quais processos de socialização foram privilegiados em nossa história. Esquece-se de aprofundar-se no peso socializador das formas precaríssimas de trabalho a que são submetidos desde crianças-adolescentes. Milhões jogados a trabalhos irrelevantes, precarizados, incertos, mal pagos e degradados.

Essas têm sido ao longo de nossa história as "pedagogias" socializadoras para o trabalho, dispensando a escola e a esfera pública, e mantendo legiões de pauperizados, desempregados, subempregados, sobrantes do mercado de trabalho. Boaventura de Sousa Santos (2006) fala-nos de uma forma de fascismo do apartheid social. Trata-se da segregação social dos excluídos por meio de uma cartografia urbana dividida em zonas selvagens e zonas civilizadas que está a transformar-se em um critério geral de sociabilidade. Esse fascismo social opera como regime civilizacional (p. 333).

Nessa persistente socialização que se opera no condicionar a produção da existência a esses padrões de trabalho e de subcidadania, fica descartável investir na socialização escolar para o trabalho e a cidadania. Fica descartável investir na afirmação de um sistema de educação. A justificativa tão repetida nos estatutos legais: a função da educação escolar é preparar; socializar para o trabalho e a cidadania perdeu força para investir realmente na construção do sistema de educação. Pesquisar, aprofundar-se e intervir nesses padrões de socialização que passam pela precarização do trabalho e da cidadania seriam um caminho para entender a história da precária construção de nosso sistema educacional e para avançar em políticas de outra construção.

O padrão de socialização pela escola será fraco enquanto continuarem eficientes outros padrões de produção-socialização dos trabalhadores e dos coletivos populares, sociais, étnicos, raciais, dos campos e das periferias: o padrão de alimentação, de sobrevivência, de renda mínima a que são submetidos, em que são socializados. Milhões submetidos à fome, à miséria, a índices de desenvolvimento sub-humano em uma economia entre as primeiras. Por aí avançamos a um dos processos de destruição do público, ou de persistente desconstrução da esfera pública: a apropriação privada do fundo público e da renda pública, a apropriação da terra, da renda da terra, da renda do trabalho para a acumulação capitalista. Para a socialização tão brutal pela subordinação do trabalho para a expropriação da terra, do espaço, da vida. Processos que têm operado de maneira brutal como socializadores do povo, dos trabalhadores mantidos à margem, inferiores, subalternos. Sem direito a ter direitos aos bens mais básicos do viver: terra, teto, trabalho, alimentação, renda, saúde, educação. Entre as pedagogias escolares de socialização e essas brutais "pedagogias" de subalternização, as elites optaram por estas, dispensando investir na construção do sistema de socialização escolar. 
Sem entender por onde têm passado em nossa formação social esses processos violentos de socialização não haverá condições de entender a secundarização dos processos de socialização via escola e sistema de educação. Os mecanismos de apropriação do fundo público, da renda pública, do trabalho, da terra desaconselham a necessidade de uma esfera pública, de instituições públicas, de gastos públicos com socialização pela escola dos próprios trabalhadores produtores da renda pública. Desaconselharam investimentos em serviços públicos de saúde, alimentação, educação, moradia, transporte, etc. Dispensaram a construção da esfera pública e de instituições e políticas públicas.

Em vez de destacar com tanta prioridade a construção desses serviços via o apelo à cooperação entre os entes federados ou via o recurso a normatizações persuasivas, será mais político privilegiar a defesa de políticas, leis efetivas, sobretudo de limitar a apropriação privada do fundo público, da renda pública. Estimular políticas, mecanismos de controle popular do fundo público, da renda pública, do trabalho e da terra. Pelo controle desses processos passa a socialização mais compulsória sobre os trabalhadores, os coletivos populares. A disputa desse controle do fundo público, da renda pública da terra e do trabalho é precondição do sistema público de educação e saúde. Para se afirmarem como espaços públicos, será necessário avançar com os próprios trabalhadores em suas lutas por construir outros padrões de trabalho, renda, do digno e justo viver.

A indistinção e a fraqueza da esfera pública não são fruto de um gesto de irresponsabilidade moral dos gestores de plantão dos entes federados, nem de falta de culturas solidárias. Mas de processos estruturantes e persistentes na nossa formação social, econômica, política. São fruto de disputas que vão muito além do apelo a culturas solidárias e de cooperação das próprias elites defensoras da apropriação privada da terra, da renda da terra e do trabalho. Como esperar que essas elites mexam nesses processos de apropriação do fundo público pela apropriação da renda da terra e do trabalho? Como esperar que privilegiem mecanismos de controle popular do fundo público e de socialização escolar renunciando ao controle da renda da terra e do trabalho, se são representantes, em sua maioria, de forças econômicas e sociais que vivem da apropriação da terra e do espaço e da renda do trabalho? Esses perversos processos ou essas "pedagogias" de produção de subalternizados dispensaram em nossa história a opção por pedagogias de socialização escolar.

A luta pela escola pública, pela esfera pública, pelo fundo-renda públicos passa pela luta contra os mecanismos brutais e contra as estruturas, os padrões de trabalho, de terra, de renda privatizados em nossa história. Passa por destruir esses mecanismos de socialização, inferiorização subalternização. As instituições públicas, o Estado e suas políticas não avançam na sua configuração como esferas públicas, de direitos, porque a indistinção entre o público e o privado e mais, a destruição 
do público, continuam uma constante da política brasileira. Com a destruição do público anulam-se a política e as políticas. Anula-se o dever do Estado na garantia dos direitos. Dispensa-se a construção de um sistema escolar de socialização.

\section{Socializados na escola na lógica pública?}

A democratização do acesso e da permanência construída nas últimas décadas pode significar a consolidação de um sistema público, de uma socialização pública? Com a chegada dos trabalhadores e de seus filhos e filhas ao sistema público de educação, estaríamos mais próximos de avançar na construção da esfera pública? Pesquisas têm mostrado que eles chegam em trabalhos e formas de sobrevivência alienantes. Que escola, que saberes curriculares e disciplinares lhes serão oferecidos? Aprenderão no tempo e na socialização escolares que essa é a vida que lhes espera, esse é o trabalho, essa é a cidadania a que são destinados? Aprenderão que sem mérito escolar, sem êxito nos percursos não terão mérito no mercado de emprego?

Em termos concretos, a lógica, o ideário, os valores da escola pública continuarão na lógica privatista e privatizante? O sistema público de educação age com os novos educandos, filhos(as) de trabalhadores com lógicas antipúblicas, privatizantes? A socialização escolar será aceita se reproduz e reafirma a socialização que essas crianças, adolescentes, jovens ou adultos trabalhadores tiveram ao longo de nossa história? A lenta e precária construção do sistema de educação aceita que se continuem e reafirmem os tradicionais processos de socialização do povo, dos trabalhadores no submetimento a trabalhos precarizados, a um viver indigno e injusto? Questões, impasses que vêm acompanhando tantos esforços pela construção de um sistema de educação realmente público que fortaleça a esfera pública.

O acesso de quase $100 \%$ dos alunos ao ensino fundamental mostra que a escola vem se consolidando como espaço público de democratização do acesso da infânciaadolescência populares, que até décadas recentes não chegavam às escolas. Formuladores de políticas, gestores, coletivos docentes, pesquisadores vêm se empenhando em construir e implementar, nas escolas e nas redes, políticas e programas que tornem a escola pública um espaço e um tempo de socialização e aprendizagem em saberes e valores, em identidades e culturas públicas, democráticas, igualitárias, de direitos.

Há um avanço no sentido de construir a escola como esfera pública de direitos pela democratização do acesso e da permanência. Entretanto, a escola só será pública se for um tempo de socialização em valores públicos. As pesquisas vêm mostrando que ainda predominam, nas escolas aonde essas crianças/adolescentes populares chegam, valores, lógicas de mérito, processos seletivos reprovadores e segregadores, classificatórios e hierarquizantes, em que são socializados, que reproduzem e reforçam sua tradicional inferiorização-subalternização nos padrões segregadores de 
poder, de trabalho, de renda, de moradia. Os índices de reprovação e de classificação dessas infâncias-adolescências populares, sua classificação como fracassados, repetentes, desacelerados, com problemas de aprendizagem, a condenação de milhares a percursos escolares truncados não são expressão de termos avançado na construçãoconsolidação de um sistema de educação pública, regido por valores de socialização públicos, igualitários. Ao contrário, ao chegarem com tanto esforço à escola pública, continuam submetidos a processos de socialização que reproduzem lógicas, valores, identidades subalternizadas dos processos de socialização a que foram e serão submetidos nos padrões de trabalho e de segregação social e racial. As políticas oficiais de avaliações externas ranqueadoras, em que essas infâncias-adolescências e suas identidades sociais, raciais, de campo, periferias aparecem como fracassadas, não apontam para valores públicos, igualitários, de socialização. Apontam para uma tensão entre valores públicos e privados na democratização da escola.

A chegada dos setores populares à escola pública vem mostrando que a construção de um sistema público não passa apenas pela democratização do seu acesso, mas por construí-lo na lógica do público e não na lógica dos valores privados do mérito ou da concorrência, da reprovação, segregação. Como não passa também por condenar essas infâncias ao simples aprendizado de competências elementaríssimas para trabalhos precaríssimos ou para uma sobrevivência imprevisível. O problema não está em não termos um sistema público, mas em que os coletivos socializados na lógica do privado, do mercado, cheguem a um sistema construído em nossa história na lógica do privado e nela sejam socializados. Os processos seletivos, reprovadores de milhões de adolescentes e jovens e até de crianças ao chegarem às escolas públicas, são um atestado de que a democratização de seu acesso não representa a consolidação de um sistema público. As lógicas hierarquizantes, ranqueadoras dos educandos e de seus coletivos sociais e raciais, não são lógicas do público.

Mantendo-se nessa lógica do privado, a construção do sistema educacional não representará um avanço na construção da esfera pública, na medida em que continua operando na socialização segregadora em que opera a esfera privada. $\mathrm{O}$ alargamento do sistema de educação não necessariamente está representando o alargamento da esfera pública como espaço de direitos, uma vez que aqueles segregados na esfera privada dos padrões de trabalho, de renda, de moradia, de terra... são submetidos a processos segregadores na própria escola pública. A cooperação entre agentes que controlaram a esfera pública na lógica dos interesses privados, que vêm se apropriando do fundo público, colaborará para desatrelar o sistema escolar dessas lógicas segregadoras?

Outro dado que revela a dificuldade de avançar na consolidação do nosso sistema público: o comportamento que os agentes gestores dos entes federados vêm tendo nas últimas décadas, negando-se a reconhecer os direitos dos trabalhadores em educação. Revelam a lógica privada em que operam e em que submetem os gastos em 
educação à acumulação de poder e de renda, ou à apropriação do fundo público, restringindo ao máximo a aplicação da renda do trabalho à garantia dos direitos próprios dos trabalhadores em educação. A tensa história de mais de três décadas de lutas do movimento docente por construir uma escola pública é mais um capítulo das resistências à afirmação da esfera pública. Os gestores dos entes federados não têm fortalecido essas lutas por direitos. $\mathrm{O}$ regime de colaboração entre entes federados com poderes e condições tão desiguais tem levado a resistir e reprimir essas lutas do movimento docente pelos direitos iguais do trabalho. Ao longo da história, as lutas pelo direito a um piso nacional salarial único e as resistências dos entes federados a sua efetivação são um exemplo das contradições na construção de um sistema articulado de educação entregue à colaboração dos entes federados.

\section{Por outros referentes de análise}

Torna-se necessário pesquisar com maior profundidade como na construção de nosso sistema educacional estiveram e estão em causa conflitos entre processos de socialização dos coletivos populares, dos trabalhadores. Até dos trabalhadores da educação. Aí radica o velho conflito entre ser socializados nas escolas ou continuar socializando-os nos brutais padrões de poder, de trabalho sub-humano, de sobrevivência nos limites, de expropriação de suas terras, espaços, territórios, renda. Essas longas tensões de opções por processos de socialização e de produção material da sociedade e dos outros pressionam o pensamento educacional a aprofundá-las, se se pretende entender a tensa e lenta construção de um sistema de educação para outra socialização dos trabalhadores.

Velhas tensões em que se enreda a lenta construção da esfera pública em nossa história. A retomada da produção social privatista na lógica de reprodução do capital, até nas instituições e políticas-programas do Estado e dos governos, põe ainda mais em causa a tênue construção da esfera e da escola públicas. Estamos em tempos de abate dos lentos avanços na sua construção. Apelar para conceitos como a cultura gestora solidária nestes tempos de parcerias público-privadas e de invasão de interesses privados na gestão da fraca esfera pública exigem análises e intervenções críticas radicais.

Esse abate dos lentos avanços feitos na construção da esfera pública e do sistema público de educação nos obriga a levar nossas análises a novos campos e com novas concepções. De um lado, retomar uma linha de pesquisa e de interpretação da história da educação, das análises de políticas em suas estreitas relações com a produção material da sociedade. Se essa linha de análise já foi central em décadas recentes, torna-se mais urgente em tempos de ocupação direta do sistema de educação, de suas políticas, de sua gestão por interesses e ganhos do capital. A educação 
passou a ser disputada como um terreno a mais de lucro, de mercado, não apenas um campo onde socializar para valores de mercado, para socializar mão de obra submissa ao padrão de trabalho explorador, mas de explorar a educação como uma empresa de lucro, desde a construção de escolas - até de educação infantil - em parcerias público-privadas até ao lucro com a venda de apostilas, do setor privado para as redes e escolas públicas, chegando à invasão de empresas de educação de fora, internacionais, privatizando nosso sistema de educação média e superior. Nas últimas décadas avançam os interesses do capital na privatização dos sistemas públicos de educação, o que afeta com nova radicalidade a construção de sistemas públicos e da esfera pública na educação.

Nesse quadro novo que avança com tanta força, resulta desfocado pensar a construção-afirmação de nosso Sistema Nacional de Educação pelo apelo à cooperação entre os entes federados. A defesa do todos - até empresários - pela educação parece ser mais de acordo com essa ocupação empresarial do sistema educacional. Sem uma maior atenção aos processos por onde passa a construção da sociedade, a correlação de forças sociais, nossas análises sobre a construção do sistema educacional ficarão distantes das tensões sociais, econômicas e políticas dessa construção.

Isolar em nossas análises o Estado e os entes federados desse quadro em que se dão as tensões na produção material da sociedade nas quais se enreda a construção do sistema educacional, e pensá-lo apenas na correlação de forças entre os atores políticos e de políticas-gestores municipais, estaduais, federais, conselhos, secretarias, MEC e até Congresso e suas decisões, é limitar uma história bem mais complexa e tensa das relações entre a construção da esfera pública, de nosso sistema de educação, e a pluralidade de atores, de forças sociais que interagem na produção material de nossa sociedade e que disputam de maneira direta a educação.

Quando se pensa a política e as políticas educacionais descoladas dessa base material de produção-reprodução da sociedade, a "Política" e as políticas ficam em um vazio explicativo. A pretensão de construir políticas e instituições por meio de acordos pelo alto, distantes dessa base material de produção da sociedade, perde radicalidade política e crítica.

É sintomático que os novos atores sociais em seus movimentos, afirmandose atores políticos e de políticas, sempre vinculem a construção de outra escola, de outra esfera pública, a outro projeto de sociedade, a outros processos de produção das bases materiais da sociedade: lutas por terra, territórios, teto, moradia, trabalho, renda, coladas ao direito ao conhecimento, à cultura, às identidades coletivas. A outra escola. Aprenderam em suas histórias e experiências sociais que o direito à educação só acontecerá pela intervenção nos processos de produção de 
outra sociedade. Consequentemente articulam as lutas por educação, por outra escola, a lutas e intervenções concretas por trabalho, renda, teto, terra... Por outro projeto de campo, de sociedade em construção.

\section{Um sistema de educação fora do lugar?}

A ênfase na urgência de construir e consolidar um sistema nacional articulado de educação parte do diagnóstico de que ele ainda ou não foi construído ou está desarticulado, atrasado no tempo e fora do lugar. O que alimenta essa análise da história do nosso sistema? O referente teórico dessas análises não está fora do lugar?

A frase de Chico de Oliveira: "No Brasil, o moderno precisa do atraso para se reproduzir" poderia ser aplicada a essas análises e ao pensamento pedagógico moderno. As análises do sistema educacional reproduzem a imagem de um sistema deslocado ou à mercê de constantes deslocamentos no percurso de nossa história social e política. Um sistema desfocado, como que levado à deriva por falta de acordos, consensos, colaborações articuladas, sobretudo entre os entes federados. Análises próximas predominam das políticas educacionais, das boas intenções que animam as nossas LDBs e tantas Diretrizes Curriculares, mas que não se traduzem em práticas quando entregues à gestão desarticulada e atrasada dos entes federados. Uma tendência a responsabilizar as lideranças gestoras por esse persistente deslocamento, de inconclusão da construção de um sistema nacional articulado, coeso. Sistema. O ideal de sistema ainda não articulado persegue o pensamento educacional.

O pensamento educacional padece dessa marca: é preciso estar em estado de permanente reconstrução de um sistema idealizado, articulado, coeso, pronto, porém nunca pronto nem coeso, nem articulado. Os termos inovar, novo sistema, nova escola, escola nova alimentam-se dessa visão de uma escola, um sistema deslocado, desfocado, que está a exigir trazê-lo ao seu lugar, ao seu ideal. Temos mais análises sobre o que o sistema ainda não é do que sobre o que realmente ele é, e sobre por que é o que é. Há uma celebração do que ainda não são o sistema, a escola, a qualidade, a formação docente... do que um reconhecimento do quanto se avançou. Por que essa ênfase no ainda não? Por que o pensamento educacional se alimentou da sociedade que não somos, do que o povo não é, do que não são os educandos, ou das carências que como coletivos trazem de seus atrasos culturais, intelectuais, morais, humanos, cidadãos. O sistema educacional ainda não é, o Brasil ainda não é porque o povo ainda não é. Essa ênfase no ainda não se alimentou das resistências e até da impossibilidade de superar tantos atrasos, carências e inferiorizações de origem, de classe, de raça, de etnia, de campo, com que as políticas sociais e educacionais se 
defrontam. Essa visão de que a educação trabalha com coletivos deslocados dos padrões de modernidade, de moralidade, racionalidade, cultura, civilidade marcou em nossa história as formas de pensar-se o próprio pensamento, o sistema e as políticas educacionais em um persistente destacar o ainda não feito, não construído, o que não é e nunca será. ${ }^{1}$

Essa visão pessimista de um pensamento deslocado se acentua na maneira de tentar trazer e aplicar aqui o pensamento, as teorias pedagógicas e as análises de currículos, de sistema de lá, das sociedades onde se supõe o sistema está pronto, a educação é de qualidade, porque o povo já é. Esse movimento de pensar nossa educação a partir das teorias, didáticas, políticas, diretrizes e índices de qualidade de lá alimenta a permanente sensação de que nossa educação, nosso sistema estão distantes da qualidade, da condição de sistema articulado, coeso, eficiente das sociedades modernas desenvolvidas. O nosso pensamento educacional, o nosso sistema, quando analisado tendo como referente o ideal de sistema, de qualidade ou as teorias pedagógicas e a sociologia do currículo de lá, termina pensando-se no exílio. $\mathrm{O}$ que termina produzindo um exílio do próprio pensamento educacional.

Ao pensar a educação pública aqui no exílio, deslocada, desarraigada, distante do pensamento e do sistema de lá, termina-se levando a culpar o nosso lugar como não lugar, a nossa sociedade e os processos reais de sua produção como culpados desse permanente deslocamento de nosso sistema, das políticas, dos currículos, do próprio pensamento educacional. Sempre fora do nosso tempo, de nosso lugar. Do nosso presente. Sempre em estado de "não ainda". A reconstrução da nossa história da educação destaca mais a história das teorias e do sistema de lá do que de cá. Conta-se essa história como tentativas fracassadas de plantar aqui ideários de lá: o humanismo renascentista, a pedagogia da Ilustração, o pensamento escolanovista, construtivista, a escola do trabalho, o ideal de docente intelectual orgânico, do currículo pós-estruturalista, pós-moderno, pós-crítico... Ou o ideal republicano de fazer do sistema público, laico, obrigatório, universal a matriz formadora do cidadão da república e da democracia idealizadas.

Ao constatar a distância entre esses ideários e a realidade da construção de nosso sistema à mercê de contínuos deslocamentos no curso de nossa história, fica a sensação de que cada percurso foi e continua sendo uma oportunidade perdida. Análises - lamento do que se pretendia e poderia ter sido, mas não foi. Não faltam análises que vão na contramão, tentando superar essa visão de deslocamento, de exílio, para buscar com lucidez os determinantes políticos e estruturais das promessas e dos ideários não cumpridos. Deixar de ver nosso sistema e nosso pensamento no exílio para pensá-lo enraizado no chão das correlações de forças, nos limites e nas possibilidades dos processos de produção material e cultural de nossa sociedade. A história de nosso sistema de educação só é compreensível na especificidade de nossa história. 
Não ver a história de nossa educação como um continuum de oportunidades perdidas de transplantar aqui teorias, didáticas, análises, epistemologias e sistemas de lá. Essa história de oportunidades perdidas tem levado a uma história de políticas de cobranças persistentes. Cobrar é uma marca de nosso pensamento educacional. Porém cobrar o quê? Cobrar o que ainda não é: o ideário não cumprido, a política fracassada, a qualidade não alcançada. Cobrar o sistema ainda não articulado. Cobrar de quem? Dos políticos, dos gestores, do Congresso, do MEC, dos entes federados. Cobrar dos professores e alunos populares que ainda não são nem cidadãos nem humanos. Nem modernos.

Cobranças parciais distantes dos processos mais determinantes que passam pela produção material e cultural de nossa sociedade. Essa lógica de análise tão persistente, ao enfatizar as oportunidades perdidas e as cobranças de reaproveitálas, exige análises críticas aprofundadas de seus limites teóricos. Exige aprofundar o que foi perdido e de quem cobrar as oportunidades perdidas. Sobretudo, exige repensar os parâmetros e ideários do que foi perdido e do que cobrar. Exige outro pensamento.

\section{Um sistema na medida dos seus destinatários}

Se reconhecemos que aqui foram ensaiadas e aplicadas políticas educativas, teorias e didáticas, que aqui foi construído o sistema de instrução pública republicano que persiste, poderíamos superar esse pensá-lo deslocado, fora de lugar, para pesquisá-lo como uma construção colada aos processos de produção de nossa sociedade. Fruto do seu lugar na correlação de forças sociais, econômicas e políticas nossas na totalidade de correlações de forças sociais e políticas mundiais.

Poderíamos ainda superar esse persistente olhar de algo que nunca foi, de oportunidades perdidas, para ver nosso sistema de educação no exato lugar social e político em que foram alocados os coletivos sociais, étnicos, raciais, dos campos e das periferias. Os outros, seus supostos destinatários. O nosso sistema não nasceu deslocado, mas no mesmo lugar de segregação - de fora de lugar, de desterritorializados a que foram e continuam relegados seus destinatários. Outras análises da história de nosso sistema de educação. Outra visão de sua articulação orgânica como lugar-nãolugar dos coletivos populares nos processos de produção de nossa sociedade.

A questão nuclear desafiante que deveria ocupar nossas pesquisas e análises sobre o sistema de educação é se, na medida em que esses coletivos não se aceitam nesse lugar e pressionam por outro lugar, será possível outro sistema. Sem dúvida que a percepção de que o nosso sistema de educação, o dever do Estado e dos entes federados para a garantia do direito popular à educação poderia ter sido outro estimulou estudos, pesquisas e tentativas de construir outro sistema mais articulado. 
Por aí apontam os apelos a políticas de responsabilização e cooperação dos entes federados. Mas será urgente reconhecer que o avanço da consciência popular por direitos poderá forçar outras cobranças. Outros referentes teóricos. Sobretudo, na medida em que esses outros sujeitos pressionam pela construção de outro projeto de sociedade e de socialização. Será aconselhável superar a lógica dualista do não plenamente realizado, do sistema ainda inconcluso, desarticulado, para um sistema colado às possibilidades e aos limites, às tensões e contradições de lutas e movimentos por outra produção material da sociedade: por reforma agrária, urbana, por outro padrão de poder, de trabalho, de produção de alimentos para a vida...

A ênfase desses movimentos na produção material da sociedade nos aconselha a vincular aí a construção do sistema educacional e não apenas as articulações de forças políticas e a imposição de determinado quadro ideológico, hegemônico. A lenta e desarticulada construção de nosso sistema de educação não se explica por um consenso ideológico, hegemônico, das elites políticas para manter o controle dos dominantes sobre os dominados. Nem como aparelho ideológico para submeter os trabalhadores e os setores populares ao controle ou à cidadania e à inclusão pelo consenso. O que em nossa história esteve em jogo em relação aos setores populares e aos trabalhadores das cidades e dos campos não foi nem é unificá-los, incorporá-los, nem sequer dominá-los pelo consenso. A tendência tem sido a de interpretar a função esperada da escola fazendo parte central no jogo de unificar pelo consenso.

O nosso padrão de dominação-subalternização sempre foi mais radical, não pensou na integração, e menos ainda no consenso por meio da passagem do povo pela escola. Os limites à integração sempre foram mais abissais entre os dominantes e dominados, entre os cidadãos de posses, de bens e de bem e os subcidadãos, entre os humanos e os sub-humanos. Esse padrão de ruptura abissal, em que opera a relação entre dominantes-dominados em nossa história social, política e cultural, dispensa o jogo de integração e unificação pelo consenso. Por aí passa, até o presente, a fraqueza do sistema escolar nunca pensado pelas elites como agência socializante da integração pelo consenso. Em um jogo de dominação-subalternização, de rupturas abissais, não caberia um jogo de amarração-socialização consensual. Nem via escola como aparelho ideológico. Fica fraco ou perde sentido político qualquer projeto dos dominantes para socializar no consenso pela escolarização pública dos(as) filhos(as) dos dominados.

Logo, as análises da construção de nosso sistema de educação, que tanto privilegiaram o jogo hegemônico das nossas elites, em busca de uma explicação - leis, decretos, pareceres, diretrizes, discursos... - para a desarticulação de nosso sistema público não são a pista mais fecunda para a reconstrução dessa história. Nem o apelo à cooperação entre as elites hegemônicas gestoras das diversas instâncias de 
governo será o melhor caminho para desta vez constituirmos um sistema articulado de consenso pela educação. Nessa história de polaridades abissais resulta ingênuo o apelo a todos pela educação.

Uma análise política mais aprofundada de por onde passou e passa o padrão de dominação-subalternização ou ruptura abissal entre dominantes e dominados e uma análise mais aprofundada de como essa ruptura tão radical dispensou a via do consenso, da unificação-integração pelo consenso, pela socialização escolar, aconselham a levar as análises ao subsolo dos vínculos entre esse padrão de poder-dominação e a fraqueza de nosso sistema de educação. Essa conexão tão estreita entre a produção do sistema de educação e os brutais e abissais processos de produção dos outros - seus destinatários - aconselha a dar maior centralidade a análises que se aprofundem nos processos de produção material da nossa sociedade, que se aprofundem no padrão racista, sexista de trabalho, de cidadania, de apropriação-expropriação da renda, da vida, da condenação a um mínimo sobreviver como processos brutais de subalternização (ARROYO, 2012).

\section{Educar para o consenso ou suprimir o dissenso?}

O discurso sobre a necessidade de um sistema articulado, de qualidade, tem destacado a necessidade de socializar os trabalhadores e os cidadãos para o consenso na cultura nacional, nos valores da ordem. Qual a força configurante desses ideais do nosso sistema de educação pública? Quando se opta por privilegiar processos de um mínimo sobreviver, não há lugar nem para o jogo do consenso nem do dissenso. Não por acaso a questão operária foi uma questão de polícia, como as questões agrária, da paz nas favelas e nos conglomerados continuam uma questão de polícia, de repressão e de extermínio. Nem de consenso, nem de dissenso. Por aí estaríamos secundarizando toda possibilidade de uma análise política da construção de nosso sistema de educação? Seria tentar ir mais fundo, priorizando as dimensões políticas que se dão nas especificidades das relações de poder-dominação-subalternização persistentes na produção de nossa sociedade que não privilegiaram o jogo do consenso-dissenso, educação para o consenso, nem sequer para se contrapor ao dissenso. Os brutais processos de um viver nos limites dos limites mantiveram os setores populares na impossibilidade de manifestar qualquer dissenso, seja como movimento operário, como movimentos sociais tratados como questões de polícia, de repressão, de extermínio de vidas e de lideranças de todo movimento de dissenso.

Depois de algumas décadas de tentar a contra-hegemonia pelo pensamento crítico, pela conscientização por currículos anti-hegemônicos, idealizados como semeadores do dissenso, o que experimentamos é que a paz nos campos, nas vilas, nos conglomerados, nas ruas e até nas escolas não passa por acentuar um sistema 
educacional que faça o jogo de consenso integrador. Ao menos desta vez, por meio de conteúdos contra-hegemônicos. Uma lição fica exposta diante de tentativas tão sérias de se contrapor ao projeto hegemônico que supúnhamos inspirava o consenso via escolarização e conteúdos curriculares a-críticos, alienantes. A lição que fica é que a lógica que inspira e inspirou a fraca construção de nosso sistema educacional é outra. Este não foi movido ou imobilizado como instituição educadora para a integração via consenso hegemônico, logo não teve relevância a tentativa de constituir a escola e os currículos como espaços de dissenso anti-hegemônico, crítico, socializador para a integração cidadã participativa.

Impressiona como nem resistência houve a essas tentativas de levar o dissenso ao sistema escolar público popular. Por quê? Talvez porque ele nunca foi pensado no jogo do consenso nem do dissenso ideológico. O que nos obriga a ir mais fundo para entender por onde têm passado, na produção material, política e cultural de nossa sociedade, as rupturas fundamentais entre dominantes e dominados-subalternizados. Rupturas que não se dão basicamente em construir ou não um significado comum, submetendo ao consenso dissensos ou significados não compartilhados, opostos, mas pela destruição do dissenso pela raiz, pelo submetimento a padrões brutais de trabalho, de sobrevivência, de vidas suspensas à mercê do padrão de poder e de trabalho, de apropriação da terra, do solo, da renda, da vida.

É significativo que, às tentativas de incorporar outros significados críticos, anti-hegemônicos, nos currículos, não se responde com reafirmação de conteúdos hegemônicos, mas com controles segregadores de sistemas de mérito, de avaliação, classificação, reprovação, inferiorização. Repondo as velhas rupturas sociais, raciais, regionais, de campo. De classes. Por aí se destroem mais uma vez as tentativas de colocar o sistema escolar no jogo do consenso-dissenso, ideológico, cooperativo.

Um momento fecundo para, a partir dos limites de tentativas tão sérias de injetar o dissenso anti-hegemônico, crítico, no suposto campo-instituição do consenso hegemônico - a escola, os currículos -, avançarmos para a questão nuclear: como vincular as possibilidades e os limites da construção do sistema de educação com as bases mais radicais e determinantes do próprio padrão hegemônico de dominaçãosubalternização, de ruptura abissal (SANTOS, 2010). Uma explosão de relações sociais de classe, raça, etnia, região a que se atrelou a produção dos outros como oprimidos, sub-humanos, subcidadãos, subtrabalhadores. Inexistentes, logo inincluíveis via consenso e desprezíveis como sujeitos de dissensos. Por aí se politiza e radicaliza a construção do sistema de educação ao politizar e radicalizar os padrões de produção material e cultural da sociedade.

É significativo que seja aí onde os coletivos segregados como inexistentes se afirmam existentes; aqueles aos quais foi negada a integração pelo consenso se afirmam em radicais dissensos sobre os projetos de campo, as políticas agrária, 
urbana, trabalhistas, de moradia, de renda, de saúde. De vida. De educação e de escola-universidade.

Por aí esses coletivos mostram que a repressão ao dissenso se dá nesses processos tão básicos de produção social e de seu viver. Não seria fecundo conectar a construção de outro sistema de educação com esses dissensos tão radicais? Com essas propostas de outro projeto de campo, de sociedade? Com outros modos de pensar-alocar esses coletivos nos padrões de terra, trabalho, moradia, renda, conhecimento, educação? Sobretudo, conectar as possibilidades de outro sistema de educação às resistências organizadas a esses padrões. Outro sistema de educação, outra esfera pública em tempos de outros sujeitos de dissensos.

\section{Nota}

1. Ver o texto instigante de Paoli (2006).

\section{Referências}

ARROYO, M.G. Los movimientos sociales y la construción del derecho a la educación. In: SACRISTÁN, J.G. (Org.). La reforma necesária: entre la política educativa y la practica escolar. Madrid: Morata, 2006.

ARROYO, M.G. Outros sujeitos, outras pedagogias. Petrópolis: Vozes, 2012.

LEAL, V.N. Coronelismo, enxada e voto. São Paulo: Cia das Letras, 1948.

MAAR, W.L. A teoria crítica da sociedade brasileira de Francisco de Oliveira. In: RIZEK, C.; ROMÃO, W. (Org.). Francisco de Oliveira: a tarefa da crítica. Belo Horizonte: UFMG, 2006.

OLIVEIRA, F. Crítica da razão dualista: o ornitorrinco. 2. ed. São Paulo: Boitempo, 2003a.

OLIVEIRA, F. A política em uma era de indeterminação: opacidade e reencantamento. In: SILVA, F.T. et al. (Org.). República, liberalismo, cidadania. Piracicaba: Unimep, 2003b.

PAOLI, M.C. Não mais e não ainda: invenção e emergência em Chico de Oliveira. In: RIZEK, C.; ROMÃO, W. (Org.). Francisco de Oliveira: a tarefa da crítica. Belo Horizonte: UFMG, 2006.

SANTOS, B.S. A gramática do tempo: por uma nova cultura política. São Paulo: Cortez, 2006. 
Reinventar a política - reinventar o sistema de educação

SANTOS, B.S. Para além do pensamento abissal: das linhas globais a uma ecologia de saberes. In: SANTOS, B.S.; MENESES, M.P. (Org.). Epistemologias do sul. São Paulo: Cortez, 2010.

Recebido em 18 de junho de 2013.

Aprovado em 16 de julho de 2013. 